\title{
Survey of Dental Abscesses in Elementary School Patients in Shiraz between Years of 2016-2017
}

\author{
Karimi M. D* \\ Internal Auditor \& Documentations at Apple Dental Clinic, Iran
}

Received: 眥 June 07, 2018; Published: 眥 June 12, 2018

*Corresponding author: Karimi, Internal Auditor \& Documentations at Apple Dental Clinic, Iran

\section{Short Communication}

Regarding the high prevalence of tooth decay and the occurrence of multiple dental abscesses in patients between ages of 7 to 9 which results in early loss of primary teeth; and consequently causes problems in chewing, occlusion and loss of space, paying attention to this matter is very essential. For this reason, a call for a routine dental examination was announced to the majority of Shiraz elementary schools by Apple Dental Clinic. Fortunately, most of them collaborated, and more than 5,000 of students took part in this survey. The project was led by Dr. Mohammad Karimi and Dr. Hassan Dehghan. It took 1 year to get the following results.

The purpose of this study was the evaluation of the prevalence of dental abscesses, treatment and healing rate in elementary schools children who were participated in Apple Dental Clinic Survey. The study was based on the clinical evaluation of children between ages of 7 to 9 with dental infections. The most prevalence was in 7 years old children. The survey showed $20 \%$ of the participant had acute dental abscesses. The most involved teeth were D and E in both arches. The major treatments were including the combination of rainage, pulpectomy and antibiotic therapy. Unfortunately $5 \%$ of treatments were not effective, resulting in tooth extraction. As the survey showed the high prevalence of dental abscesses in primary molars, it is strongly emphasized to maintain these teeth before the eruption of permanent molars occurs. It is necessary to do early diagnosis and treatment of dental caries and abscesses before it is too late.

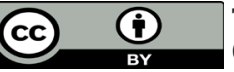

This work is licensed under Creative Commons Attribution 4.0 License

To Submit Your Article Click Here: Submit Article

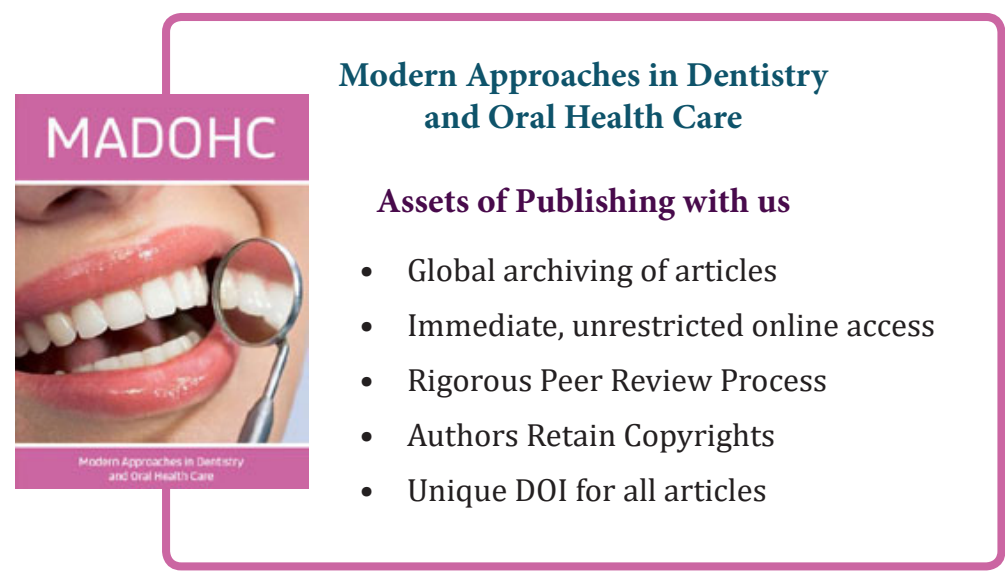

